\title{
Updating Bridge Reliability Based on Bridge Management Systems Visual Inspection Results
}

\author{
Allen C. Estes, M.ASCE, ${ }^{1}$ and Dan M. Frangopol, F.ASCE ${ }^{2}$
}

\begin{abstract}
Bridge management systems have become increasingly sophisticated over the past decade and provide valuable information about the structural condition of all bridges in the national database. At the same time, reliability methods have gained increasing prominence and are used to forecast life-cycle performance over many decades of structural life. Such reliability analyses need to be updated based on the results of inspections. Specifically targeted nondestructive evaluations are the preferred solution, but are not always available for every bridge. This paper examines how the visual inspection data provided from bridge management systems already in place can be used to update the reliability of a bridge. The limitations and necessary modifications to current practice are discussed. The superstructure of a Colorado highway bridge deteriorating due to corrosion is used as an example.
\end{abstract}

CE Database subject headings: Bridges, highway; Management systems; Limit states; Structural reliability; Bridge inspection; Rehabilitation; Colorado.

\section{Introduction}

The United States has invested billions of dollars in civil infrastructures (buildings, airports, roads, dams, etc.), which support commerce and economic progress. As a subset, the nation maintains and monitors an inventory of almost 600,000 highway bridges that support a vast network of roads and highways. Most of these highway bridges were constructed during the 1930s in response to the depression or during the 1950s, 1960s, and 1970s as part of the interstate highway construction. The former are reaching the end of their useable lives and the latter are beginning to require major repairs (AASHTO 1993). The replacement and repairs of these bridges will cost $\$ 10.6$ billion per year over the next ten years, just to overcome current deficiencies in highway bridges (ASCE 2001).

The problem is one of scarce resources. States have competing priorities for the same tax dollars and even those funds which are specifically allocated to bridge maintenance and repair must be used efficiently to ensure the most critical bridges are addressed first. The 1991 Intermodal Surface Transportation Efficiency Act requires state transportation departments to implement bridge management systems to more efficiently plan maintenance, monitor condition of bridges, and allocate resources. The stated objective of these bridge management systems is to help engineers and other decision makers determine when and where to spend bridge

\footnotetext{
${ }^{1}$ Associate Professor, Dept. of Civil and Mechanical Engineering, United States Military Academy, West Point, NY 10996. E-mail: ia2804@exmail.usma.edu

${ }^{2}$ Professor, Dept. of Civil, Environmental, and Architectural Engineering, Univ. of Colorado, Boulder, CO 80309-0428. E-mail: Dan.Frangopol@colorado.edu
}

funds in order to enhance public safety, preserve existing infrastructure, and serve commerce (AASHTO 1993). The inspection results of the bridges and culverts in the National Bridge Inventory are reported to the Federal Highway Administration in a standardized format (FHWA 1988). The data collected over several decades has provided researchers and managers with a valuable resource to make informed decisions and to predict future bridge behavior. The system ensures that every bridge is inspected at least every two years and the improvements in computer capabilities over the past 20 years have made the data collection, consolidation, and analysis much easier to manipulate and more powerful in its capability.

A second trend that has evolved largely because of increased computer capability is the development and use of more rigorous analysis and design methods for structures where uncertainty in loads and/or resistances and/or modeling are quantified to a greater degree. Both component and system reliability methods are gaining greater acceptance and seeing increased usage for evaluating structures (Frangopol et al. 1998). While reliability methods are quite powerful for quantifying risk and uncertainty, they require a great deal of input data to execute.

These two trends have progressed simultaneously and independently (Estes et al. 2002). A time-dependent reliability analysis requires a number of assumptions about the loading, resistance, and deterioration models. These models predict the future

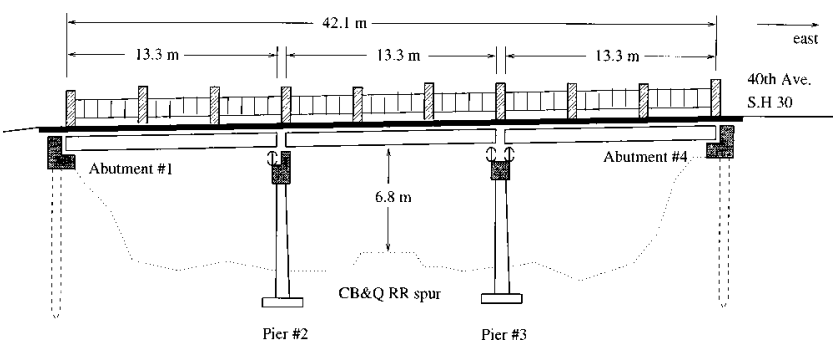

Fig. 1. Profile of Colorado State Highway Bridge E-17-AH 


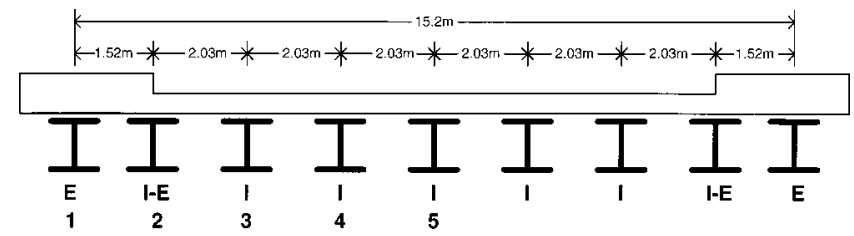

Fig. 2. Layout of girders on superstructure of Bridge E-17-AH

structural performance and are the basis for optimum life-cycle inspection and repair planning. The models must be updated over time to revise the optimum maintenance strategy based on how a structure actually behaves. The best sources of data to do this are specific nondestructive evaluations (NDE) taken at optimum time intervals. Such methods investigate the specific defect or parameter that needs to be updated. The problem is that these methods are often expensive, time consuming, and resource-intensive to execute over a large series of bridges.

This paper will examine to what degree the data obtained from the bridge management systems already being used by the States can be used to update the reliability of individual bridges. The PONTIS Bridge Management System (PONTIS 1995) has been adopted by most states and relies on biennial visual inspections of every bridge. Although visual inspections are regularly conducted and the data is recorded and readily available, these results cannot be used in their current form to update the reliability of a structure. The visual inspections were developed for a different purpose. Bridge management systems were designed to make decisions on all bridges in a network over time (AASHTO 1993), but with some revisions and conservative assumptions, the data can be incorporated effectively into the reliability analysis of a specific bridge structure. A specific Colorado highway bridge is used as an example and the specific deterioration mechanism of steel corrosion is addressed since it can be visually assessed and provides a straightforward application.

\section{Reliability Analysis of Highway Bridge}

A time-dependent reliability analysis of Bridge E-17-AH, a typical simply supported, nine-girder bridge in the metro-Denver area of Colorado was conducted. The complete analysis was presented in Estes and Frangopol (1999) and part is summarized herein. The bridge has three spans of equal length $(13.3 \mathrm{~m})$ and a total length of $42.1 \mathrm{~m}$ as shown in Fig. 1. The cross-section of the bridge superstructure is shown in Fig. 2. The steel girders supporting the concrete slab are standard-rolled, compact, noncomposite shapes. The steel girders are classified as interior (I), exterior (E), and interior-exterior (I-E) and are stiffened by end diaphragms and intermediate diaphragms at the third points. As shown in Fig. 2, Girder 1 is an exterior (E) girder and carries only pedestrian traffic and an occasional emergency vehicle; Girder 2 is an interiorexterior (I-E) girder which supports normal traffic only from the right portion of the slab; and Girders 3, 4, and 5 are interior (I) girders, which carry traffic loads from both sides of the slab.

The bridge was modeled as a series-parallel system of 16 separate failure modes described in detail in Estes and Frangopol (1999). Each girder was examined with respect to the shear and flexural limit states. The random variables included material strength, model uncertainty, girder distribution factors, and material dimensions that could not be measured directly. The limit state equations for an interior girder with respect to shear and moment, respectively, are

$$
\begin{aligned}
g_{\text {int-shear }}(x)= & V_{\text {capacity }}-V_{\text {demand }}=10.55 F_{y} \gamma_{\mathrm{msg}}-18.04 \lambda_{\text {conc }} \\
- & 5.26 \lambda_{\text {asph }}-2.89 \lambda_{\text {steel }}-28.33 V_{\text {trk }-i} D F_{i} i_{\text {beam }}=0 \\
g_{\text {int-moment }}(x)= & M_{\text {capacity }}-M_{\text {demand }}=39.8 F_{y} \gamma_{\text {mfg }}-197.65 \lambda_{\text {conc }} \\
& -57.64 \lambda_{\text {asph }}-31.7 \lambda_{\text {steel }}-M_{\text {trk-i }} D F_{i} i_{\text {beam }}=0
\end{aligned}
$$

\begin{tabular}{|c|c|c|c|}
\hline Definition and units of random variables & Notation & Mean value and standard deviation & Reference \\
\hline Uncertainty factor: live load shear on interior girders ${ }^{\mathrm{a}}$ & $V_{\text {trk- } i}$ & $(1.38 ; 0.1656)^{\mathrm{b}}$ & Nowak (1993) \\
\hline Uncertainty factor: live load shear on exterior girders & $V_{\text {trk-e }}$ & $(1.38 ; 0.1656)$ & Nowak (1993) \\
\hline Yield strength of steel in girders (MPa) & $F_{y}$ & $(252.5,29.0)$ & Nowak (1993) \\
\hline Uncertainty in live load girder distribution: interior girders & $D F_{i}$ & $(1.309 ; 0.163)$ & Zokaie et al. (1991) \\
\hline $\begin{array}{l}\text { Uncertainty in live load girder distribution: interior-exterior } \\
\text { girders }\end{array}$ & $D F_{i-e}$ & $(1.14 ; 0.142)$ & Zokaie et al. (1991) \\
\hline Uncertainty in live load girder distribution: exterior girders & $D F_{e}$ & $(0.982 ; 0.122)$ & Zokaie et al. (1991) \\
\hline Uncertainty factor: impact on girders & $i_{\text {beam }}$ & $(1.14 ; 0.114)$ & Nowak et al. (1994) \\
\hline Live load moment on interior girders $(\mathrm{kNm})$ & $M_{\text {trk-i }}$ & $(579.4 ; 69.6)$ & Nowak (1993) \\
\hline Live load moment on exterior girders $(\mathrm{kNm})$ & $M_{\text {trk-e }}$ & $(474.1 ; 56.9)$ & Nowak (1993) \\
\hline Uncertainty factor: weight of truck on bridge & $\gamma_{\text {trk }}$ & $(1.38 ; 0.1656)$ & Nowak (1993) \\
\hline Model uncertainty: shear in steel & $\gamma_{\mathrm{msg}}$ & $(1.14 ; 0.137)$ & Nowak (1993) \\
\hline Model uncertainty: flexure in steel & $\gamma_{\mathrm{mfg}}$ & $(1.11 ; 0.128)$ & Nowak (1993) \\
\hline Uncertainty factor: weight of asphalt & $\lambda_{\text {asph }}$ & $(1.0 ; 0.25)$ & Nowak (1993) \\
\hline Uncertainty factor: weight of concrete & $\lambda_{\text {conc }}$ & $(1.05 ; 0.105)$ & Nowak (1993) \\
\hline Uncertainty factor: weight of steel & $\lambda_{\text {steel }}$ & $(1.03 ; 0.082)$ & Nowak (1993) \\
\hline
\end{tabular}

where the random variables, their parameters, and their source are listed in Table 1.

Table 1. Random Variables Used in Reliability Analysis of Girders

\footnotetext{
${ }^{a}$ Random variables without units are dimensionless.

${ }^{\mathrm{b}}$ Mean values $\mu$ and standard deviations $\sigma$ are indicated in parentheses $(\mu ; \sigma)$.
} 
Table 2. Descriptors of Random Variables $A$ and $B$ for Predicting Corrosion Propagation in Bridge Girders (Albrecht and Naeemi 1984)

\begin{tabular}{lcc}
\hline Random variable & $A$ & $B$ \\
\hline Interior girders (Environment 2) & & \\
$\quad$ Mean value & 34.0 & 0.65 \\
Coefficient of variation & 0.09 & 0.10 \\
Correlation coefficient & $0.0^{\mathrm{a}}$ & - \\
$\quad$ & \\
$\quad$ between $A$ and $B$ & & \\
Exterior and interior-exterior girders (Environment 1) & 0.593 \\
$\quad$ Mean value & 80.2 & 0.40 \\
Coefficient of variation & 0.42 & - \\
Correlation coefficient & 0.68 & \\
$\quad$ between $A$ and $B$ & & \\
${ }^{\mathrm{a}}$ Correlation data not available, variables assumed to be uncorrelated.
\end{tabular}

The bridge live load model (Nowak 1993) predicts maximum moments and shears for different span lengths. The model was developed from assembled data from 9,250 trucks and included number of axles, axle spacing, axle loads, and gross weight of vehicles. The result was a series of graphs based on the statistics of extreme values where the probability of encountering a large truck at the extreme tail of the distribution increases as more and more trucks pass over the bridge. As the number of truck passes increases, the maximum moment approaches a Type I extreme distribution. This model can be used for a bridge of any length if the average daily truck traffic is known and if it is believed that the trucks in the database are representative of the trucks going over the bridge.

Meanwhile, the steel girders are corroding over time and the section loss reduces the resistance of the girders with respect to

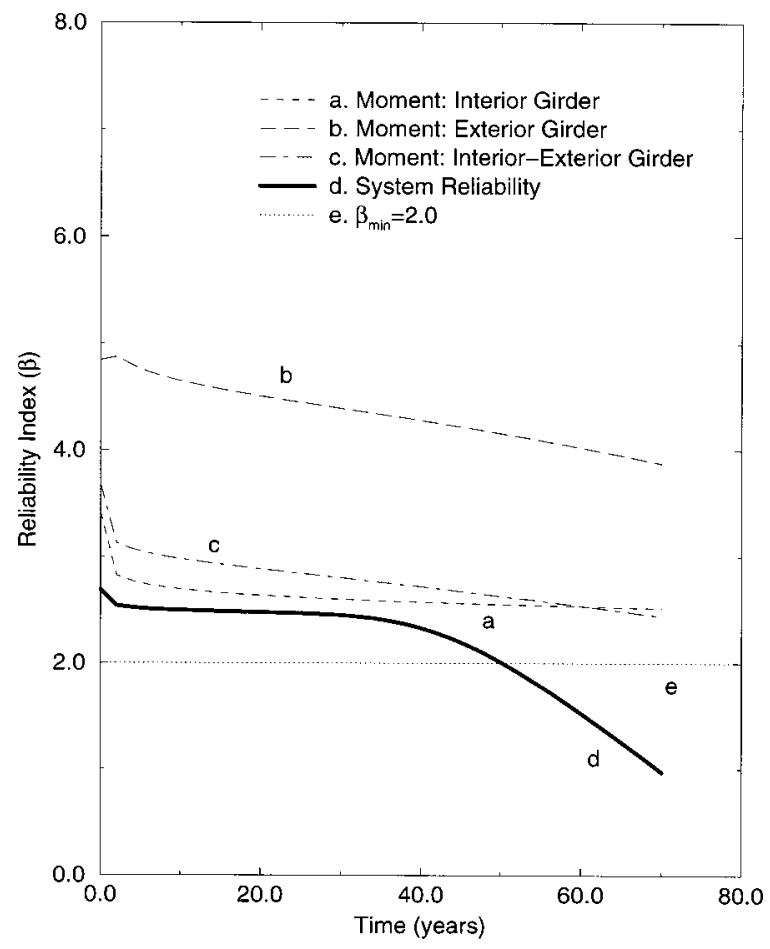

Fig. 3. System and girder moment component reliability over time for Bridge E-17-AH

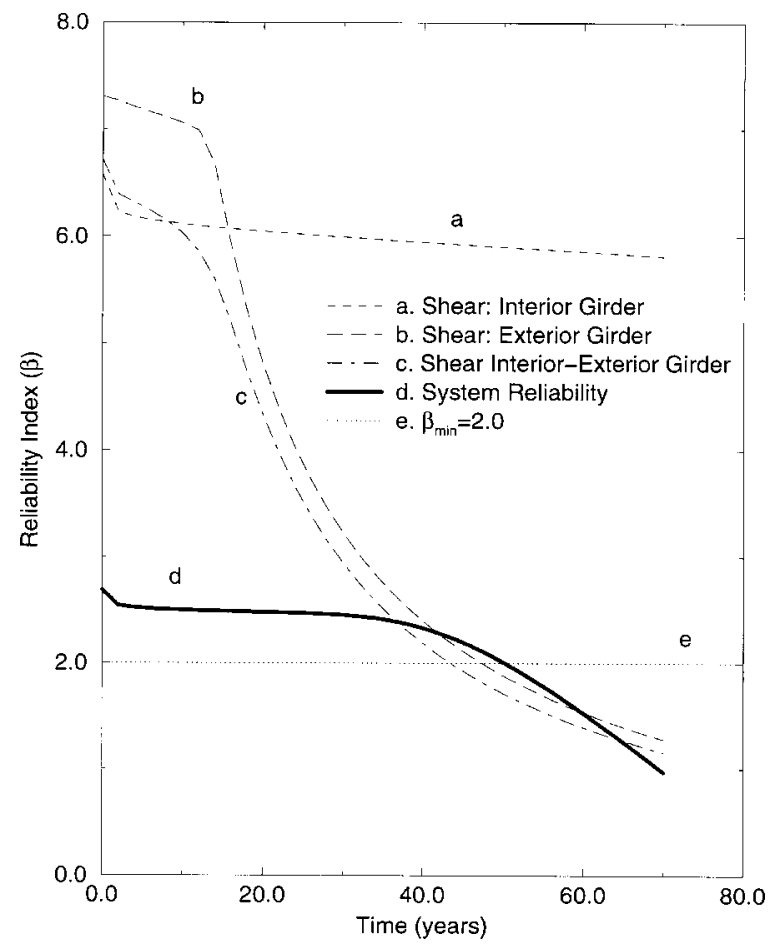

Fig. 4. System and girder shear component reliability over time for Bridge E-17-AH

both moment and shear. The corrosion penetration was based on a model developed by Albrecht and Naeemi (1984), which predicted corrosion loss using regression analysis from the field results in 46 locations. The corrosion penetration $C(t)$ in micrometers $(\mu \mathrm{m})$ at any time $(t)$, where $t$ is in years, is expressed as

$$
C(t)=A t^{B}
$$

where $A$ and $B=$ regression parameters based on environment and type of steel. The probabilistic descriptors of $A$ and $B$ associated with the bridge girders are shown in Table 2. The interior girders were assumed to be more sheltered from the sulfur oxides, nitrogen oxides, and other urban contaminants that cause corrosion than the exterior and interior-exterior girders.

The assumed corrosion pattern for the girders and the reduction in shear and moment capacity is determined by the resulting reduction in the area of the web and the diminished plastic section modulus are indicated in Estes and Frangopol (1999). As the load increases and the capacity decreases over time, the reliability of the bridge girders and of the entire bridge system is reduced as time passes. Based on the models described herein, Figs. 3 and 4 show the reliability of the girders with respect to moment and shear, respectively over a 70-year time period. The computation of the system reliability is described in Estes and Frangopol (1999).

The reliability analysis forms the basis for life-cycle planning for the bridge, but the analysis is only as good as the models which support it. Periodic inspections are needed to determine if the structure is deteriorating as predicted. Ideally, a physical measurement of the thickness of the girders is the most valid approach and would provide the best data for updating the reliability analysis. If an NDE inspection is not available, this paper investigates whether or not the visual inspection data collected from a bridge management system can be used instead. 
Table 3. CDOT (1995) Suggested Condition State Ratings for Element 107: Painted Open Steel Girders (First Three Columns) Plus Necessary Revisions (Columns 4 and 5) to Update Reliability (Estes et al. 2002)

\begin{tabular}{|c|c|c|c|c|}
\hline Condition state & Description & Rust code & Section loss ${ }^{\mathrm{a}}$ & Density distribution $^{\mathrm{a}}$ \\
\hline 1 & $\begin{array}{l}\text { No evidence of active corrosion. Paint system is sound and } \\
\text { protecting the girder. }\end{array}$ & - & $0-2 \%$ & Lognormal \\
\hline 2 & Slight peeling of the paint, pitting, or surface rust, etc. & Light R1 & $0-5 \%$ & Normal \\
\hline 3 & Peeling of the paint, pitting, surface rust, etc. & $\mathrm{R} 1$ & $0-10 \%$ & Normal \\
\hline 4 & Flaking, minor section loss ( $<10 \%$ of original thickness). & $\mathrm{R} 2$ & & \\
\hline 4 & $\begin{array}{l}\text { Flaking, swelling, moderate section loss }(>10 \% \text { but }<30 \% \text { of } \\
\text { the original thickness). Structural analysis not warranted. }\end{array}$ & $\mathrm{R} 3$ & $10-30 \%$ & Normal \\
\hline 5 & $\begin{array}{l}\text { Flaking, swelling, moderate section loss }(>10 \% \text { but }<30 \% \text { of } \\
\text { the original thickness). Structural analysis not warranted due to } \\
\text { location of corrosion on member. }\end{array}$ & $\mathrm{R} 3$ & & \\
\hline 5 & $\begin{array}{l}\text { Heavy section loss ( }>30 \% \text { of original thickness), may have } \\
\text { holes through base metal. }\end{array}$ & $\mathrm{R} 4$ & $>30 \%$ & Lognormal \\
\hline
\end{tabular}

${ }^{\mathrm{a}}$ Not part of the PONTIS definition-created to quantify the observed corrosion.

\section{Pontis Inspections}

As already indicated, the PONTIS Bridge Management System (PONTIS 1995) has been adopted by most states and relies on biennial visual inspections of every bridge. PONTIS assigns condition ratings to various bridge elements including components such as railings, joints, or decks; types of materials such as concrete, steel, or timber; and other relevant information such as protected or unprotected decks, open or closed girders, and painted or unpainted stringers.

In the PONTIS system, each element is visually inspected by a trained inspector and classified into one of five condition states, although some elements have fewer condition states. The bridge element, which evaluates the amount of corrosion on the steel bridge girders, is Element 107 (CDOT 1995) shown in Table 3. While the degree of thickness loss is helpful, there are two prob- lems with using this inspection data to update the reliability. The results report linear feet of girder in each condition state but do not show on which girder or where on a specific girder the corrosion is located. If the corrosion is located on the web near the support, the shear failure mode will be most affected; whereas, if the corrosion is on the flanges in the middle of the beam, the moment limit state is most affected. Second, the thickness loss due to corrosion should be assessed in probabilistic terms to be used effectively in a reliability analysis. While this is not possible from a visual inspection, some conservative assumptions can be made which will at least provide a worst-case assessment of the reliability and may generate the requirement for a more detailed and focused NDE inspection.

Hearn and Frangopol (1996) and Renn (1995) suggested a segment-based inspection as an improvement to the current

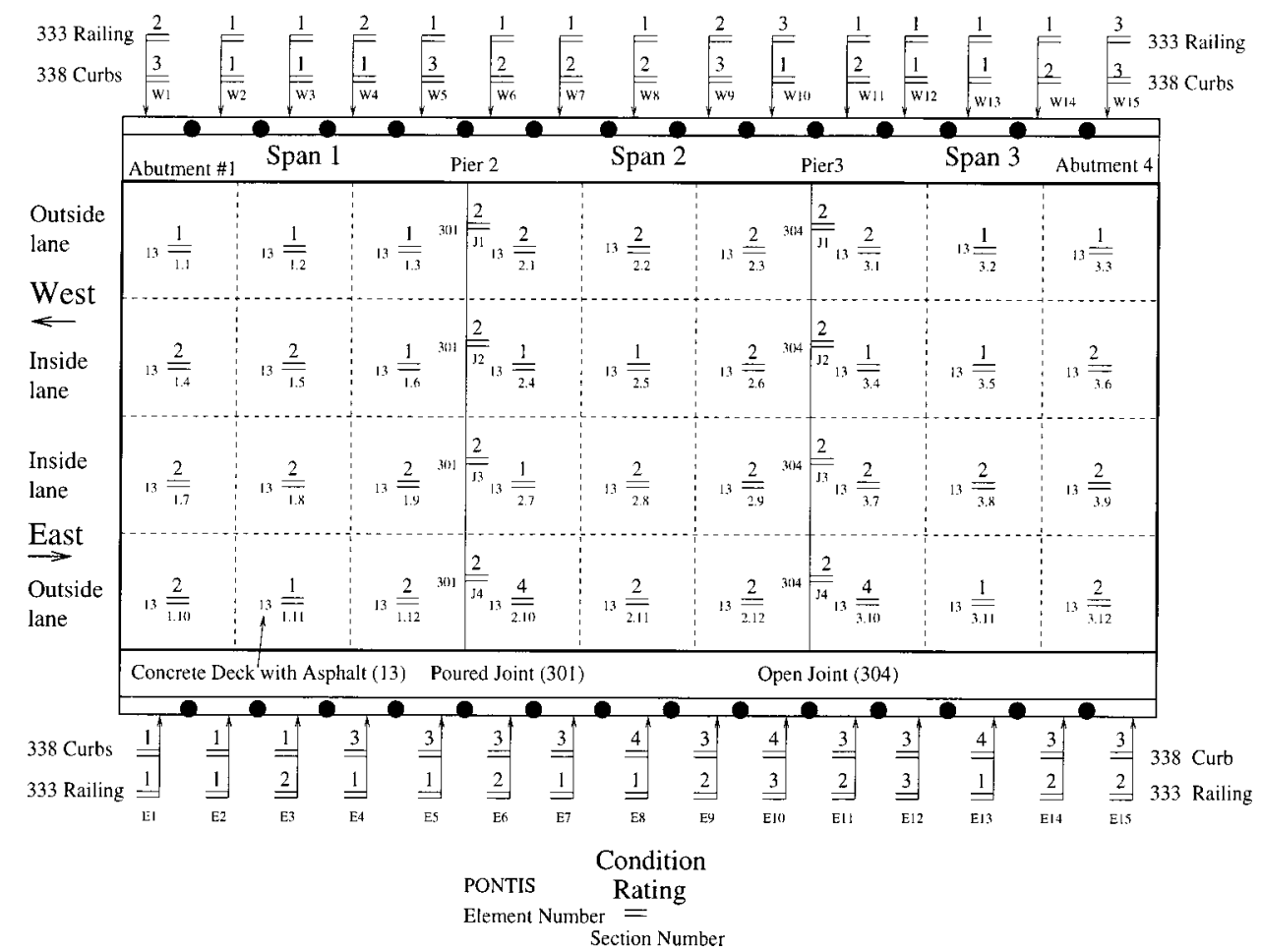

Fig. 5. Segment-based inspection results for top of concrete deck 


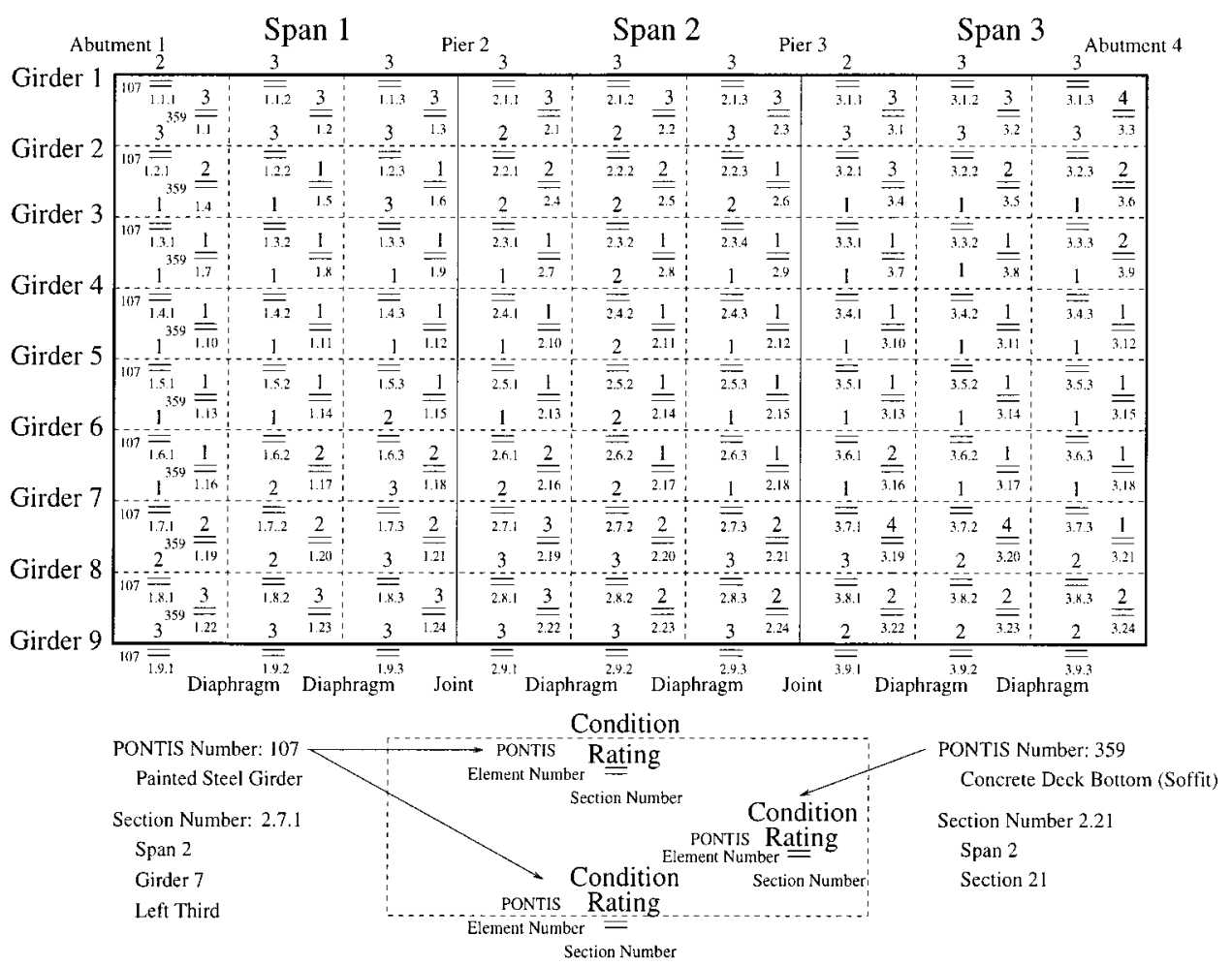

Fig. 6. Segment-based inspection results for bottom of concrete deck and superstructure

PONTIS inspection where condition state ratings are applied to specific locations on the bridge structure. The revision is totally compatible with PONTIS condition states and flags, requires little additional documentation, and adequately addresses the deficiency of location. The bridge is divided into small, easily definable segments and each segment is rated separately. The condition rating for each segment is recorded on a drawing of the structure, so that the location of the defect is part of the inspection report. A complete segment-based inspection was conducted on Bridge E-17-AH and the condition of the top of the concrete deck is shown in Fig. 5. The inspection results include the condition of the concrete deck (Element 13), the joints (Elements 301 and 304), the curb sections (Element 338) and the railings (Element 333). The results for the corrosion of the girders (Element 107) and the bottom of the concrete slab (Element 359) are shown in Fig. 6. The complete inspection results for the remainder for the bridge are shown in Estes (1997). While preliminary work in developing the drawing is required, the actual inspection takes no additional time using the segment-based approach. It requires the same amount of time to rate each section individually as it does to

Table 4. Results of Segment-Based Inspection for Interior Girders where Moment Capacity is Critical

\begin{tabular}{|c|c|c|c|c|c|c|}
\hline \multicolumn{7}{|c|}{ Interior girders-Moment: Condition rating $\mathrm{CS}=2$} \\
\hline \multirow{2}{*}{$\begin{array}{l}\text { Girder } \\
\text { number }\end{array}$} & \multicolumn{2}{|c|}{ Span 1} & \multicolumn{2}{|c|}{ Span 2} & \multicolumn{2}{|c|}{ Span 3} \\
\hline & Section & Rating & Section & Rating & Section & Rating \\
\hline 1 & 1.3 .2 & 1 & 2.3 .2 & 2 & 3.3 .2 & 1 \\
\hline 2 & 1.4 .2 & 1 & 2.4 .2 & 2 & 3.4 .2 & 1 \\
\hline 3 & 1.5 .2 & 1 & 2.5 .2 & 2 & 3.5 .2 & 1 \\
\hline 4 & 1.6 .2 & 1 & 2.6.2 & 2 & 3.6 .2 & 1 \\
\hline 5 & 1.7 .2 & 2 & 2.7 .2 & 2 & 3.7 .2 & 1 \\
\hline
\end{tabular}

Note: Section locations (e.g., 1.3.2) are defined in Fig. 6, count the number of linear feet of girder that are in each condition state and the former is far more useful.

The relevant inspection results are shown in a tabular format in Tables 4-7. Table 4 shows the condition rating of all girder segments on interior girders where the moment capacity is the critical failure mode. For this simply supported structure, the middle section of the interior five girders from all three spans are included in the analysis. Because the assumption of perfect correlation between these girders was made in the analysis, the condition state assigned to all interior girders was the lowest rating received for any individual girder. For the interior girders with respect to moment, the composite rating was condition state $\mathrm{CS}$ $=2$ where six of the 15 sections received this rating. If the ratings on these girders differed wildly, the assumption of perfect correlation would have to be revisited.

Table 5. Results of Segment-Based Inspection for Interior Girders where Shear Capacity is Critical

\begin{tabular}{|c|c|c|c|c|c|c|}
\hline \multicolumn{7}{|c|}{ Interior girders-Shear: Condition rating $\mathrm{CS}=3$} \\
\hline \multirow{2}{*}{$\begin{array}{l}\text { Girder } \\
\text { number }\end{array}$} & \multicolumn{2}{|c|}{ Span 1} & \multicolumn{2}{|c|}{ Span 2} & \multicolumn{2}{|c|}{ Span 3} \\
\hline & Section & Rating & Section & Rating & Section & Rating \\
\hline \multirow[t]{2}{*}{1} & 1.3 .1 & 1 & 2.3 .1 & 2 & 3.3 .1 & 1 \\
\hline & 1.3 .3 & 3 & 2.3 .3 & 2 & 3.3 .3 & 2 \\
\hline \multirow[t]{2}{*}{2} & 1.4 .1 & 1 & 2.4 .1 & 1 & 3.4 .1 & 1 \\
\hline & 1.4 .3 & 1 & 2.4 .3 & 1 & 3.4 .3 & 1 \\
\hline \multirow[t]{2}{*}{3} & 1.5 .1 & 1 & 2.5.1 & 1 & 3.5 .1 & 1 \\
\hline & 1.5.3 & 1 & 2.5 .3 & 1 & 3.5 .3 & 1 \\
\hline \multirow[t]{2}{*}{4} & 1.6 .1 & 1 & 2.6.1 & 1 & 3.6 .1 & 1 \\
\hline & 1.6 .3 & 2 & 2.6 .3 & 1 & 3.6 .3 & 1 \\
\hline \multirow[t]{2}{*}{5} & 1.7 .1 & 1 & 2.7 .1 & 2 & 3.7 .1 & 1 \\
\hline & 1.7 .3 & 3 & 2.7 .3 & 1 & 3.7 .3 & 1 \\
\hline
\end{tabular}

Note: Section locations (e.g., 1.3.3) are defined in Fig. 6. 
Table 6. Results of Segment-Based Inspection for Interior-Exterior Girders for Both Shear and Moment Capacity

\begin{tabular}{|c|c|c|c|c|c|c|}
\hline \multirow{2}{*}{$\begin{array}{l}\text { Girder } \\
\text { number }\end{array}$} & \multicolumn{2}{|c|}{ Span 1} & \multicolumn{2}{|c|}{ Span 2} & \multicolumn{2}{|c|}{ Span 3} \\
\hline & Section & Rating & Section & Rating & Section & Rating \\
\hline \multicolumn{7}{|c|}{ Interior-exterior girders-Moment: Condition rating $\mathrm{CS}=3$} \\
\hline 2 & 1.2 .2 & 3 & 2.2 .2 & 2 & 3.2 .2 & 3 \\
\hline 8 & 1.8 .2 & 2 & 2.8 .2 & 3 & 3.8 .2 & 2 \\
\hline \multicolumn{7}{|c|}{ Interior-exterior girders-Shear: Condition Rating $\mathrm{CS}=3$} \\
\hline 2 & 1.2 .1 & 3 & 2.2 .1 & 2 & 3.2 .1 & 3 \\
\hline \multirow{3}{*}{8} & 1.2 .3 & 2 & 2.2 .3 & 3 & 3.2 .3 & 3 \\
\hline & 1.8 .1 & 2 & 2.8 .1 & 3 & 3.8 .1 & 3 \\
\hline & 1.8 .3 & 3 & 2.8 .3 & 3 & 3.8 .3 & 2 \\
\hline
\end{tabular}

Note: Section locations (e.g., 1.2.1) are defined in Fig. 6.

Table 5 shows the same inspection results for interior girders where shear capacity is critical, which are the end sections for this bridge. The rating is $\mathrm{CS}=3$ because two out of the 30 sections received this rating. One could make a case for reclassifying girders based on this information where Girders 4, 5, and 6 which are closer to the center of the bridge are clearly deteriorating more slowly than are Girders 3 and 7 which are closer to the exterior of the bridge. Tables 6 and 7 show the same results for the interiorexterior girders and the exterior girders. These girders were rated as $\mathrm{CS}=3$ for both shear and moment failure modes.

To translate the condition states into probabilistic terms, it was assumed that condition state deterioration over time was linear and the deterioration intensity was normally distributed. To ensure the model was conservative, it is also assumed that a bridge element is initially at the halfway point of a specific condition state and progressively shifts to the right over time (Frangopol and Estes 1997). The standard deviation of the distribution is determined by the quality of the inspection program. Fig. 7 shows the probabilistic distribution for condition state 4 (CS4) when the inspector is correct $90 \%$ of the time. The mean value starts at $\mu$ $=20 \%$ section loss the first time an inspector classifies a girder as CS4. The standard deviation $\sigma=6.08$ is based on the inspector being wrong ten percent of the time by erring on the high side and low side with equal frequency. The mean value increases linearly until it reaches a maximum value of $\mu=30 \%$ section loss where it will remain until an inspector classifies the girder as CS5 in a future inspection. The model is conservative and in the extreme case, could be off by as much as half a condition state. Most often, it will be less.

The study considered three possible inspection programs where the inspectors were qualified as very experienced, experi-

Table 7. Results of Segment-Based Inspection for Exterior Girders for Both Shear and Moment Capacity

\begin{tabular}{|c|c|c|c|c|c|c|}
\hline \multirow{2}{*}{$\begin{array}{l}\text { Girder } \\
\text { number }\end{array}$} & \multicolumn{2}{|c|}{ Span 1} & \multicolumn{2}{|c|}{ Span 2} & \multicolumn{2}{|c|}{ Span 3} \\
\hline & Section & Rating & Section & Rating & Section & Rating \\
\hline \multicolumn{7}{|c|}{ Exterior, girders-Moment: Condition rating $\mathrm{CS}=3$} \\
\hline 1 & 1.1 .2 & 3 & 2.1 .2 & 3 & 3.1 .2 & 3 \\
\hline 9 & 1.9 .2 & 3 & 2.9 .2 & 3 & 3.9 .2 & 2 \\
\hline \multicolumn{7}{|c|}{ Exterior Girders-Shear: Condition Rating $\mathrm{CS}=3$} \\
\hline 1 & 1.1.1 & 2 & 2.1 .1 & 3 & 3.1 .1 & 2 \\
\hline \multirow{3}{*}{9} & 1.1.3 & 3 & 2.1.3 & 3 & 3.1 .3 & 2 \\
\hline & 1.9 .1 & 3 & 2.9 .1 & 3 & 3.9 .1 & 3 \\
\hline & 1.9 .3 & 3 & 2.9 .3 & 3 & 3.9 .3 & 2 \\
\hline
\end{tabular}

Note: Section locations (e.g., 1.1.3) are defined in Fig. 6.

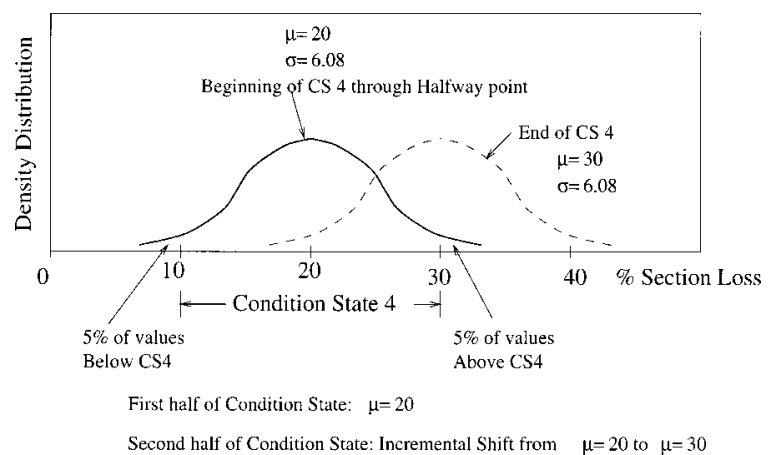

Fig. 7. Conservative random distribution of deterioration for PONTIS Element 107 in condition state 4 when inspectors are correct $90 \%$ of time

enced, and inexperienced and the correct ratings could be expected 95,85 , and $75 \%$ of the time, respectively (Frangopol and Estes 1997). The quality of the inspection program was determined using seven criteria implemented by the Colorado DOT (Estes 1997). Those criteria include the presence of a quality insurance inspector to verify field reports; rotation of different inspectors through the same bridges; number of years experience of inspectors; a formal certification program; periodic meetings to address issues, questions, and discrepancies; availability of training for both new and veteran inspectors; and a written supplement to make any condition state descriptions clearer and less ambiguous. For the very experienced inspectors, the probability density distributions associated with CS1 through CS5 for girder corrosion (Element 107) are shown in Fig. 8 (Frangopol and Estes
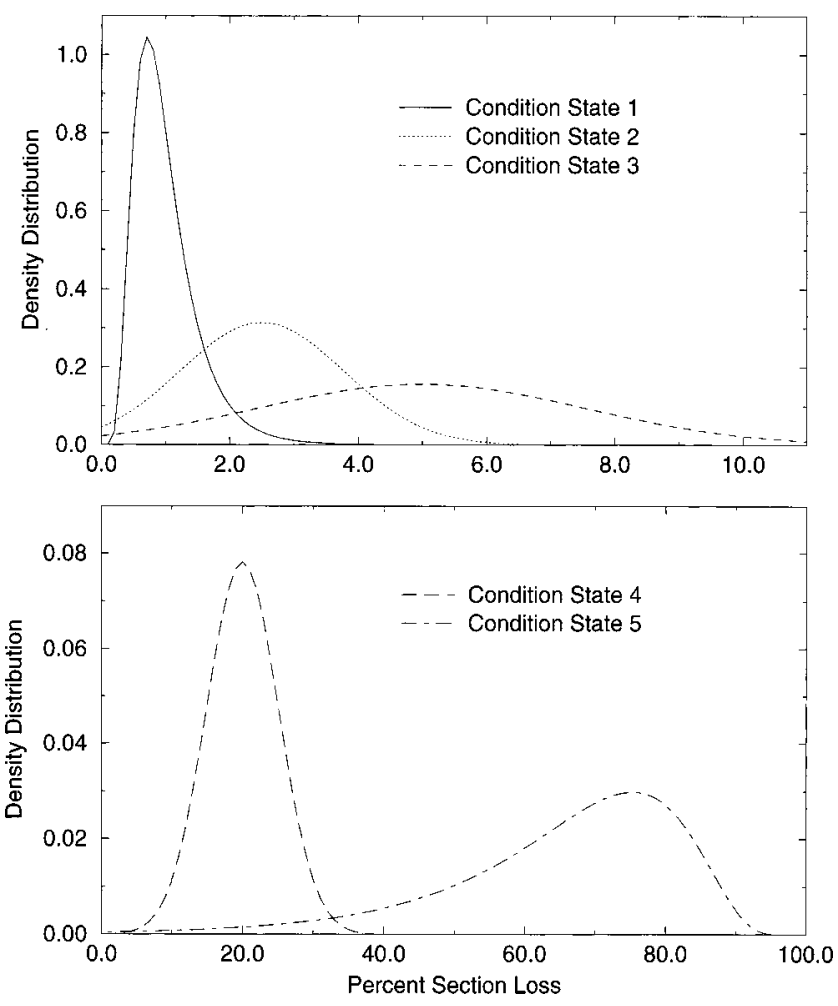

Fig. 8. Probability density distributions associated with condition state (CS) ratings CS1-CS5 for PONTIS Element 107: Painted open steel girders for inspection category A (very experienced inspectors) 
Table 8. Comparison of Girder Reliability Index $\beta$ on Bridge E-17-AH Based on Inspection Results and Deterioration Model Prediction (Estes et al. 2002)

\begin{tabular}{|c|c|c|c|c|c|c|}
\hline \multirow{2}{*}{$\begin{array}{l}\text { Girder number and } \\
\text { failure mode }\end{array}$} & \multirow[b]{2}{*}{ Condition state } & \multirow[b]{2}{*}{ Girder type } & \multirow[b]{2}{*}{ Model prediction, $\beta$} & \multicolumn{3}{|c|}{ Reliability index inspection results } \\
\hline & & & & Very experienced, $\beta$ & Experienced, $\beta$ & Inexperienced, $\beta$ \\
\hline V-1 & 3 & $\mathrm{E}$ & 1.73 & 6.81 & 6.67 & 5.76 \\
\hline $\mathrm{V}-2$ & 3 & I-E & 1.57 & 5.62 & 5.28 & 4.60 \\
\hline $\mathrm{V}-3$ & 3 & I & 5.88 & 5.36 & 5.02 & 4.43 \\
\hline M-1 & 3 & $\mathrm{E}$ & 4.11 & 4.38 & 4.38 & 4.37 \\
\hline M-2 & 3 & I-E & 2.60 & 2.78 & 2.78 & 2.78 \\
\hline M-3 & 2 & I & 2.55 & 2.54 & 2.53 & 2.53 \\
\hline
\end{tabular}

1997). The distributions are normal with the exception of the first and last condition states, which are assumed to be lognormal to reflect that the section will not increase in area due to corrosion (CS1) and that negative area for a cross-section is not possible (CS5). The condition state definitions for CS1, CS2, and CS3 were modified to reflect section losses of $0-2 \%, 0-5 \%$, and $0-10 \%$ as shown in Table 3 . The modifications were needed to add specificity to the condition states and to be able to distinguish between condition states 1,2 , and 3 .

With the randomness of the corrosion parameters conservatively defined, the section loss is estimated and the area of the web and plastic section modulus at the time of inspection are computed. The results are used to revise the shear and moment capacities of the girders and to update their reliabilities. The bridge was placed in service in 1942 . Table 8 shows the reliabilities of selected shear and moment limit states on the girders based on the original deterioration model at the time of the inspection and the inspection results obtained from a segment-based inspection with very experienced, experienced, and inexperienced inspectors. The notations V-1 and M-1 indicate the shear and moment failure modes on Girder 1 as labeled in Fig. 2, and so forth. The deterioration model for the interior girders tracks well with the inspection results for both shear and moment. The deteriora- tion model for shear deterioration on the exterior girders clearly needs to be revised as the girders are not deteriorating as quickly as expected.

\section{Bayesian Updating}

Bayesian updating techniques are very useful when faced with two sets of uncertain information and a planner needs to know which to believe. Bayesian updating uses both the prior information and new inspection information to account for the relative uncertainty associated with each.

Assume that prior to an inspection, a random variable $\Theta$ was believed to have a density function $f^{\prime}(\Theta)$ where $\Theta$ is the parameter of that distribution (i.e., the deterioration model). During an inspection, a set of values $x_{1}, x_{2}, \ldots, x_{n}$ representing a random sample from a population $X$ with underlying density function $f(x)$ are observed and are fit to a new density function $f\left(x_{i}\right)$ (i.e., the visual inspection results). The updated or posterior density function $f^{\prime \prime}(\Theta)$ which uses both sets of information and provides the best use of both can be expressed as (Ang and Tang 1975)

$$
f^{\prime \prime}(\Theta)=k L(\Theta) f^{\prime}(\Theta)
$$

where $L(\Theta)=$ likelihood function; and $k=$ normalizing constant. For the case where both $f^{\prime}(\Theta)$ and $f(x)$ are normally distributed,

Table 9. Comparison of Area of Web $\left(A_{w}\right)$ and Plastic Section Modulus $(Z)$ Results for Girders 1-5 Based on Deterioration Model Prediction, Inspection Results, and Updated Posterior Distribution

\begin{tabular}{|c|c|c|c|c|c|c|c|c|}
\hline \multicolumn{9}{|c|}{ Area of web $\left(A_{w}\right)$} \\
\hline \multirow{2}{*}{$\begin{array}{l}\text { Shear failure mode } \\
\text { in girders } 1 \text { to } 5\end{array}$} & \multirow[b]{2}{*}{ Condition state } & \multirow[b]{2}{*}{ Girder type } & \multicolumn{2}{|c|}{ Model prediction } & \multicolumn{2}{|c|}{ Inspection results } & \multicolumn{2}{|c|}{ Posterior distribution } \\
\hline & & & $\mu^{\prime}\left(\mathrm{cm}^{2}\right)$ & $\sigma^{\prime}\left(\mathrm{cm}^{2}\right)$ & $\mu\left(\mathrm{cm}^{2}\right)$ & $\sigma\left(\mathrm{cm}^{2}\right)$ & $\mu^{\prime \prime}\left(\mathrm{cm}^{2}\right)$ & $\sigma^{\prime \prime}\left(\mathrm{cm}^{2}\right)$ \\
\hline $\mathrm{V}-1$ & 3 & E & 90.9 & 44.05 & 99.1 & 8.26 & 98.7 & 8.13 \\
\hline $\mathrm{V}-2$ & 3 & $\mathrm{I}-\mathrm{E}$ & 93.0 & 44.12 & 99.6 & 9.09 & 99.3 & 8.90 \\
\hline $\mathrm{V}-3$ & 3 & I & 109.9 & 4.06 & 99.6 & 9.09 & 108.2 & 3.74 \\
\hline $\mathrm{V}-4$ & 2 & I & 109.9 & 4.06 & 108.6 & 4.52 & 109.3 & 3.03 \\
\hline $\mathrm{V}-5$ & 1 & I & 109.9 & 4.06 & 113.8 & 1.81 & 113.2 & 1.68 \\
\hline \multicolumn{9}{|c|}{ Plastic section modulus $(Z)$} \\
\hline \multirow{2}{*}{$\begin{array}{l}\text { Moment failure mode } \\
\text { in girders } 1 \text { to } 5\end{array}$} & \multirow[b]{2}{*}{ Condition state } & \multirow[b]{2}{*}{ Girder type } & \multicolumn{2}{|c|}{ Model prediction } & \multicolumn{2}{|c|}{ Inspection results } & \multicolumn{2}{|c|}{ Posterior distribution } \\
\hline & & & $\mu^{\prime}\left(\mathrm{cm}^{2}\right)$ & $\sigma^{\prime}\left(\mathrm{cm}^{2}\right)$ & $\mu\left(\mathrm{cm}^{2}\right)$ & $\sigma\left(\mathrm{cm}^{2}\right)$ & $\mu^{\prime \prime}\left(\mathrm{cm}^{2}\right)$ & $\sigma^{\prime \prime}\left(\mathrm{cm}^{2}\right)$ \\
\hline M-1 & 3 & $\mathrm{E}$ & $2,727.1$ & 200.60 & $2,750.9$ & 40.64 & $2,750.3$ & 39.99 \\
\hline M-2 & 3 & I-E & $2,909.0$ & 221.24 & $2,944.4$ & 45.15 & $2,943.1$ & 44.51 \\
\hline M-3 & 2 & I & $2,994.7$ & 19.35 & $2,987.6$ & 21.93 & $2,991.5$ & 14.19 \\
\hline M-4 & 2 & I & $2,994.7$ & 19.35 & $2,987.6$ & 21.93 & $2,991.5$ & 14.19 \\
\hline M-5 & 2 & I & $2,994.7$ & 19.35 & $2,987.6$ & 21.93 & $2,991.5$ & 14.19 \\
\hline
\end{tabular}

Note: Inspection results based on a very experienced inspector.

$\mu$ and $\sigma$ are the mean values and standard deviations for the respective distributions. 
Table 10. CDOT (1995) Suggested Condition State Ratings for Element 12: Concrete Deck-Bare

\begin{tabular}{ll}
\hline $\begin{array}{l}\text { Condition } \\
\text { state }\end{array}$ & \multicolumn{1}{c}{ Description } \\
\hline 1 & $\begin{array}{l}\text { No repaired areas, no spalls/laminations exist } \\
\text { Repaired areas/spalls/delamination area is } 2 \% \text { or less } \\
\text { of deck surface } \\
\text { Repaired areas/spalls/delamination area is } 10 \% \text { or less } \\
\text { of deck surface }\end{array}$ \\
3 & $\begin{array}{l}\text { Repaird areas/spalls/delamination area is more than } \\
10 \% \text { but less than } 25 \% \text { of deck surface } \\
\text { Repaired areas/spalls/delamination area is more than } \\
25 \% \text { of deck surface }\end{array}$ \\
\hline
\end{tabular}

the posterior function $f^{\prime \prime}(\Theta)$ is also normally distributed and has the mean value and standard deviation, respectively, as

$$
\mu^{\prime \prime}=\frac{\mu\left(\sigma^{\prime}\right)^{2}+\mu^{\prime}(\sigma)^{2}}{\left(\sigma^{\prime}\right)^{2}+(\sigma)^{2}}, \quad \sigma^{\prime \prime}=\sqrt{\frac{\left(\sigma^{\prime}\right)^{2}(\sigma)^{2}}{\left(\sigma^{\prime}\right)^{2}+(\sigma)^{2}}}
$$

where $\mu, \mu^{\prime}$, and $\mu^{\prime \prime}=$ mean values of the inspection results, the prior distribution, and the posterior distribution, respectively, and $\sigma, \sigma^{\prime}$, and $\sigma^{\prime \prime}=$ standard deviations of those same distributions.

Table 9 shows the updated parameters for the web areas and plastic section moduli for the five girders after accounting for both the inspection results and the prior deterioration model. The inspection results had the largest effect on the posterior distribution for the exterior and interior-exterior girders because the uncertainty associated with the deterioration model was so high. Where the relative uncertainties between the deterioration model and the inspection results were about the same (i.e., Girder 4), both were given about equal weight in determining the posterior distribution. Had any of the girders been classified as CS5, the large scatter reflected in Fig. 8 would reduce the influence of the inspection on the posterior distribution. The uncertainty associated with the posterior distribution will always be less than that associated with either the prior distribution or the inspection results. Table 9 is based on a very experienced inspector. With a less experienced inspector and the associated increased scatter of the results, the inspection results would have less effect on the posterior distribution.

The same approach is taken to revise the deterioration model, which determines thickness loss due to corrosion. Bayesian techniques establish new regression parameters $A$ and $B$ in Eq. (3). An updated time-dependent reliability analysis is completed and the life-cycle maintenance and repair plan for the structure is modified accordingly. Another update can be performed in two years when new inspection results are available. Enright and Frangopol (1999) provide further information on using Bayesian updating to predict the condition of concrete bridges.

Table 11. CDOT (1995) Suggested Condition State Ratings for Element 358: Smart Flag_Deck Cracking

\begin{tabular}{lcccc}
\hline & \multicolumn{4}{c}{$\begin{array}{c}\text { Condition states for cracks in concrete deck } \\
\text { spacings }(S) \text { of cracks }(\mathrm{m})\end{array}$} \\
\cline { 2 - 6 } Crack width $(\mathrm{mm})$ & $>3$ & $2-3$ & $1-2$ & $<1$ \\
\hline$<1$ & 1 & 1 & 2 & 3 \\
$1-2$ & 1 & 2 & 3 & 4 \\
$2-3$ & 2 & 3 & 4 & 4 \\
$>3$ & 3 & 3 & 4 & 4 \\
\hline
\end{tabular}

\section{Other Deterioration Modes}

With some minor modifications, the reliability of the girders were updated using visual inspection results. This would not have been possible however if the girders had not been exposed. A tougher challenge occurs on the concrete deck where the failure mechanism is corrosion of the embedded reinforcement due to a critical concentration of chlorides which have penetrated the concrete. The visual inspection results in PONTIS on concrete decks are obtained from assessing the percentage of spalls and delaminations in the deck (Element 12) as shown in Table 10 and from measuring the width and spacing of cracks (Element 358) in the concrete as shown in Table 11 (CDOT 1995). Unless some logical connection can be made between this information and the concentration of chlorides at the reinforcing steel, it is difficult to use this information to update the reliability of the deck. Attempting to infer the randomness of section loss of the reinforcement from the observed number and width of cracks, degree of efflorescence, and percentage of surface spalls merits further study.

The same problem occurs with fatigue where the fatigue life is modeled and estimated from the number of loading cycles and the stresses they produce in the members. Visual inspection data provide no useful information until visible cracks start to appear in the structural members. The presence of cracks can offer valuable information, but they will not appear until late into the fatigue life of the structure. The lack of cracks at various points in time may indicate the deterioration model is too conservative, but offers no useful information for updating the model.

Another potential area of research is to establish correlation between visual inspection results and the corresponding NDE results for the same defect. This would strengthen the value and credibility of the visual inspections and allow visual inspections to be used in combination. The applicability is probably strongest for fatigue where both visual inspections and a variety of NDE techniques are commonly used.

\section{Conclusions}

As both reliability analyses and systematic inspection programs using bridge management systems gain increased usage and prominence, it becomes more important to use the information from routine visual inspections to update lifetime reliability assessments and resulting life-cycle inspection/repair strategies. The solution will not always be straightforward, but it would be wasteful not to use this existing information in a meaningful way. Most often some conservative assumptions will be necessary. Visual inspection data will never be a substitute for a well-designed NDE inspection for a particular defect, but it can certainly be a useful supplement. This paper illustrated how routine visual information can be used to update the reliability of highway bridges subject to corrosion. The potential exists to do the same for fatigue and concrete slab deterioration, but will take further research and a stronger correlation between what the inspector sees and the actual deterioration status of the structure. Engineers who develop inspection systems and those who perform reliability analyses need to communicate during the development process to maximize the effectiveness of inspection data.

\section{Acknowledgments}

The partial financial support of the U.S. National Science Foundation through Grant Nos. CMS-9912525 and CMS-0217290 is 
gratefully acknowledged. The opinions and conclusions presented is this paper are those of the writers and do not necessarily reflect the views of the sponsoring organization.

\section{References}

AASHTO. (1993). Guidelines for bridge management systems, American Association of State Highway and Transportation Officials, Washington, D.C.

Albrecht, P., and Naeemi, A. H. (1984). "Performance of weathering steel in bridges." National cooperative highway research program, Rep. 272, Transportation Research Board, Washington, D.C.

Ang, A. H.-S., and Tang, W. H. (1975). Probability concepts in engineering planning and design, I, basic principles, Wiley, New York.

ASCE. (2001). 2001 Report card for America's infrastructure, 〈www.asce.org/reportcard〉, ASCE, Reston, Va.

Colorado Department of Transportation (CDOT). (1995). BMS/PONTIS bridge inspection manual, Colorado Dept. of Transportation, Denver.

Enright, M. P., and Frangopol, D. M. (1999). "Condition prediction of deteriorating concrete bridges." J. Struct. Eng., 125(10), 1118-1124.

Estes, A. C. (1997). "A system reliability approach to the lifetime optimization of inspection and repair of highway bridges." $\mathrm{PhD}$ thesis, Dept. of Civil, Environmental, and Architectural Engineering, Univ. of Colorado, Boulder, Colo.

Estes, A. C., and Frangopol, D. M. (1999). "Repair optimization of highway bridges using system reliability approach." J. Struct. Eng., 125(7), 766-775.

Estes, A. C., Frangopol, D. M., and Foltz, S. D. (2002). "Using visual inspection results to update reliability analyses of highway bridges and river lock structures." Proc., 8th Int. Conf. on Structural Safety and Reliability, ICOSSAR'01, Newport Beach, California, June 1722, 2001, Sweets \& Zeitlinger Publishers, Lisse, The Netherlands, 8 pages on CD-ROM.

Federal Highway Administration (FHWA). (1988). "Recording and coding guide for the structural inventory and appraisal of the nations' bridges." Rep. No. FHWA-ED-89-044, U.S. Dept. of Transportation, Washington, D.C.

Frangopol, D. M., and Estes, A. C. (1997). "Lifetime bridge maintenance strategies based on system reliability." Struct. Eng. Int. (IABSE, Zurich, Switzerland), (7)3, 193-198.

Frangopol, D. M., Ghosn, M., Hearn, G., and Nowak, A. (1998). "Structural reliability in bridge engineering." J. Bridge Eng., 3(4), 151-154.

Hearn, G., and Frangopol, D. M. (1996). "Segment-based reporting for element level bridge inspection." Proc., 4th NSF National Workshop on Bridge Research in Progress, Buffalo, N.Y., National Science Foundation, Washington, D.C., 33-38.

Nowak, A. S. (1993). "Calibration of LRFD bridge design code." Final Rep. NCHRP 12-33, Dept. of Civil and Environmental Engineering, Univ. of Michigan, Ann Arbor, Mich.

Nowak, A. S., Yamani, A. S., and Tabsh, S. W. (1994). "Probabilistic models for resistance of concrete bridge girders." ACI Struct. J., 91(3), 269-276.

PONTIS. (1995). User's manual, Release 3.0, Cambridge Systematics, Inc., Cambridge, Mass.

Renn, D. P. (1995). "Segment-based inspection for load rating within bridge management systems." Masters thesis, Dept. of Civil, Environmental, and Architectural Engineering, Univ. of Colorado, Boulder, Colo.

Zokaie, T., Imbsen, R., and Osterkamp, T. (1991). "Distribution of wheel loads on highway bridges." Transportation Research Record 1290, Volume 1, Transportation Research Board, Washington, D.C. 